\title{
Numerical and experimental study on integration of control actions into the finite element solutions in smart structures
}

\author{
L. Malgaca* and H. Karagülle \\ Department of Mechanical Engineering, Dokuz Eylül University, 35100, Bornova / Izmir, Turkey
}

Received 26 February 2008

Revised 2008

\begin{abstract}
Piezoelectric smart structures can be modeled using commercial finite element packages. Integration of control actions into the finite element model solutions (ICFES) can be done in ANSYS by using parametric design language. Simulation results can be obtained easily in smart structures by this method. In this work, cantilever smart structures consisting of aluminum beams and lead-zirconate-titanate (PZT) patches are considered. Two cases are studied numerically and experimentally in parallel. In the first case, a smart structure with a single PZT patch is used for the free vibration control under an initial tip displacement. In the second case, a smart structure with two PZT patches is used for the forced vibration control under harmonic excitation, where one of the PZT patches is used as vibration generating shaker while the other is used as vibration controlling actuator. For the two cases, modal analyses are done using chirp signals; Control OFF and Control ON responses in the time domain are obtained for various controller gains. A non-contact laser displacement sensor and strain gauges are utilized for the feedback signals. It is observed that all the simulation results agree with the experimental results.
\end{abstract}

Keywords: Smart structures, active control, piezoelectric, finite element method

\section{Introduction}

Using piezoelectric smart structures for the active vibration control problems has great potential in mechanical, aircraft, space, and civil structures [1-4]. The first step to study active vibration control problems is to develop mathematical models of open loop systems. The implementation of closed loop control actions is the next stage. The mathematical models are usually derived by using the finite element (FE) method [5-7]. Commercial programs such as ANSYS, ABAQUS and MSC/NASTRAN can be used to obtain the mathematical models. The FE matrices can be exported to other computer programs such as MATLAB to perform closed loop vibration control analyses. Closed loop responses are obtained from the block diagrams built in the program. Block diagrams requires constructing the state space models of the systems and defining controllers, inputs, feedback signals and outputs.

MATLAB scripts are used to assemble the dynamic equations after modeling the smart structure by MSC/NASTRAN in [8]. The state space equations based on the FE modal analysis in ANSYS are established and carried out the optimal control design in MATLAB [9]. A numerical model of a beam structure with PZT actuator obtained in the ANSYS-MATLAB platform is studied for vibration attenuation [10]. The model is validated by experiments using shunting circuits by means of the FE analysis optimization. The analysis is extended to a chassis sub frame of a car as a complex structure in both the experiment and ANSYS. The FE simulation and the LQ optimal control of a smart plate is studied in [11]. Control performance of a piezoelectric cantilever plate under sine wave and

*Corresponding author. Tel.: +90 232 3883138/130; Fax: +90 232 3887868; E-mail: levent.malgaca@ deu.edu.tr. 
white noise disturbances is tested experimentally by using neural network [12]. A new FE model for a piezoelectric beam is proposed using Timoshenko beam for each layer, and also used ANSYS [13].

Integration of control actions into the finite element model solutions (ICFES) is realized by Karag ülle et al. [14]. Both the FE modeling and the closed loop control actions for smart structures are achieved in ANSYS. This approach makes the active vibration control analyses in smart structures easier. This technique is also used in $[15,16]$. In reference [15], closed loop simulation of a smart beam is performed by incorporating LQG control law into the ANSYS finite element model. The structural responses obtained by the FE simulations are used for the explicit state space model by employing observer/Kalman filter identification technique. In reference [16], an experimental study is given for impulse and random excitations to verify the results obtained in [15].

In this study, active control of free and forced vibrations in piezoelectric smart structures is realized both numerically and experimentally. Numerical simulations are carried out using the ICFES method. The method was developed by Karagülle et al. [14] and simulation results were given only. Details of the method are given in this paper. Also, the simulation results obtained with displacement and strain feedback controls are verified by the experiments.

\section{Simulation}

ANSYS (10.0) has different elements to model a piezoelectric smart structure [17]. In the present work, SOLID45 and SOLID5 elements are used for the passive and the active parts, respectively. The constitutive equations and the equations of motion for piezoelectric smart structures are summarized below.

\subsection{The finite element formulation for piezoelectric materials}

SOLID45 is defined by eight nodes having three degrees of freedom (ux, uy, uz) at each node: translation in the nodal $\mathrm{x}, \mathrm{y}, \mathrm{z}$ directions. SOLID5 has a 3D piezoelectric and structural capability between the fields. The element has eight nodes, four degrees of freedom (ux, uy, uz, volt) at each node. The constitutive equations [18] to model piezoelectric materials are given as

$$
\begin{aligned}
& \{T\}=[c]\{S\}-[e]\{E\} \\
& \{D\}=\left[e^{T}\right]\{S\}+[\varepsilon]\{E\}
\end{aligned}
$$

where mechanical variables $T$ and $S$ are stress and strain vectors; electrical variables $D$ and $E$ are electrical displacement and electric field vectors, respectively. Matrices $[c],[e]$ and $[\varepsilon]$ are piezoelectric material properties, where $[c]$ is the elasticity matrix, $[e]$ is the piezoelectric matrix and $[\varepsilon]$ is the dielectric matrix.

After the application of the variational principle and FE discretization, the coupled piezoelectric FE formulation can be derived in terms of nodal quantities [17],

$$
\left[\begin{array}{l}
{[M][0]} \\
{[0]}
\end{array}\left[\begin{array}{l}
{[0]}
\end{array}\right]\left\{\begin{array}{l}
\{\ddot{u}\} \\
\{\ddot{V}\}
\end{array}\right\}+\left[\begin{array}{l}
{[C][0]} \\
{[0][0]}
\end{array}\right]\left\{\begin{array}{l}
\{\dot{u}\} \\
\{\dot{V}
\end{array}\right\}+\left[\begin{array}{l}
{[K]} \\
{\left[K^{Z}\right]^{T}\left[K^{z}\right]}
\end{array}\right]\left\{\begin{array}{l}
\{u\} \\
\{V\}
\end{array}\right\}=\left\{\begin{array}{l}
\{F\} \\
\{L\}
\end{array}\right\}\right.
$$

where, $[M]$ is the mass matrix derived from density and volume, $[K]$ is the mechanical stiffness matrix derived from elasticity matrix, $\left[K^{z}\right]$ is the piezoelectric stiffness matrix derived from piezoelectric matrix, $\left[K^{d}\right]$ is the dielectric stiffness matrix derived from dielectric matrix, $\{u\}$ and $\{V\}$ are the vectors of nodal displacements and electrical potentials, $\{F\}$ and $\{L\}$ are the vectors of mechanical force and charge, respectively.

Structural damping matrix $[C]$ is defined as linear combination of mass and mechanical stiffness matrices as follows,

$$
C=\alpha[M]+\beta[K]
$$

where the variables $\alpha$ and $\beta$ are the Rayleigh damping coefficients. Material property matrices, load and boundary conditions are required to solve Eq. (3). 


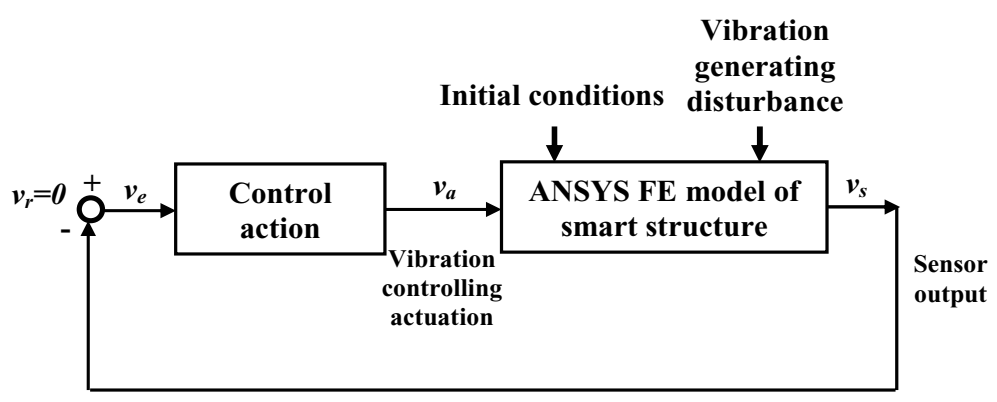

Fig. 1. Block diagram of the ICFES.

Table 1

ICFES part of APDL macro for Case 1

\begin{tabular}{|c|c|}
\hline incon.txt & ! Replace by "excite.txt" for Case 2 \\
\hline do,i,1,ns & ! Loop from $\mathrm{i}=1$ to $\mathrm{ns}$ \\
\hline time, $\mathrm{i}^{*} \mathrm{dt}$ & ! Assign time value \\
\hline solve & ! Instantaneous solution of Eq.(3) \\
\hline sensorv.txt & ! Run commands given below and read sensor value \\
\hline $\mathrm{va}(\mathrm{i})=\mathrm{kp} * \mathrm{kv}^{*}(0-\mathrm{vs}(\mathrm{i}))$ & ! Calculate controlling voltage \\
\hline d, na, volt, va(i) & ! Assign controlling voltage at node na \\
\hline$!-$ & $\begin{array}{l}\text { ! Add command: } d, n h \text {,volt, } v h(i) \text { for Case } 2 \\
\text { ! to assign excitation voltage at node } n h\end{array}$ \\
\hline \multicolumn{2}{|r|}{ 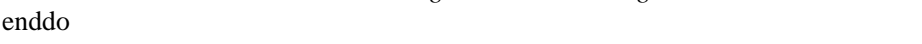 } \\
\hline \multicolumn{2}{|c|}{ "Sensorv.txt" for strain feedback control } \\
\hline *get,ux1, node, n1, u ,x & ! Read ux at node $n 1$ \\
\hline get, $\mathrm{ux} 2$, node, $\mathrm{n} 2, \mathrm{u}, \mathrm{x}$ & ! Read ux at node $n 2$ \\
\hline $\mathrm{vs}(\mathrm{i})=\mathrm{ks} *(\mathrm{ux} 2-\mathrm{ux} 1) / \mathrm{dx}$ & ! Calculate strain voltage \\
\hline \multicolumn{2}{|c|}{ "Sensorv.txt" for displacement feedback control } \\
\hline get, dz, node, $\mathrm{nr}, \mathrm{u}, \mathrm{z}$ & ! Read uz at node $n r$ \\
\hline $\operatorname{vs}(\mathrm{i})=\mathrm{ks}^{*} \mathrm{dz}$ & ! Calculate displacement voltage \\
\hline
\end{tabular}

\subsection{Integration of control actions into the finite element solutions}

The ICFES is described in this section. The block diagram of the method is shown in Fig. 1. Material properties, finite elements and boundary conditions are defined to construct the FE model. The aluminum beam and each PZT patch are meshed into 360 elements $(90 \times 4)$ and 20 elements $(5 \times 4)$, respectively. So, the FE model has 380 elements, 940 nodes for Case 1 and 400 elements, 970 nodes for Case 2. VOLT degrees of freedom for the nodes at the top and bottom faces of PZT patches are coupled with the command $c p$. First, the modal analysis is performed to find natural frequencies and mode shapes. FE modeling and modal analysis can be done by using graphical user interface (GUI) or ANSYS parametric design language (APDL). The details of these are not given here, and the readers are referred to the manuals and other references $[14,17,19]$. Block Lanczos method is used for the modal solution. Eigenvalues can be found by using the damped option.

Let $f_{h}$ be the undamped frequency and $\xi_{h}$ be damping ratio for the highest mode to be considered. The time step for the transient analysis, $d t$, is taken as equal to $1 /\left(20 \mathrm{f}_{h}\right)$. The time at which the observation is stopped, $\mathrm{t}_{s}$, is taken as equal to $1 /\left(3 \xi_{h} \mathrm{f}_{h}\right)$.

Two cases are considered in this work. Case 1 is about controlling free vibration under initial conditions. Case 2 is about controlling forced vibration under harmonic excitation. Strain and displacement feedbacks are studied for both cases.

The ICFES part for the APDL macro corresponding to the block diagram in Fig. 1 is given in Table 1 for Case 1. "incon.txt" is the file which consists of commands for the assignment of initial values. In order to assign the initial values to all nodes, a static analysis is performed first. A tip displacement $\left(\delta_{0}\right)$ in the $\mathrm{z}$ direction is applied to the nodes at the free end. The displacements for all the nodes are obtained by the static solution. These nodal 


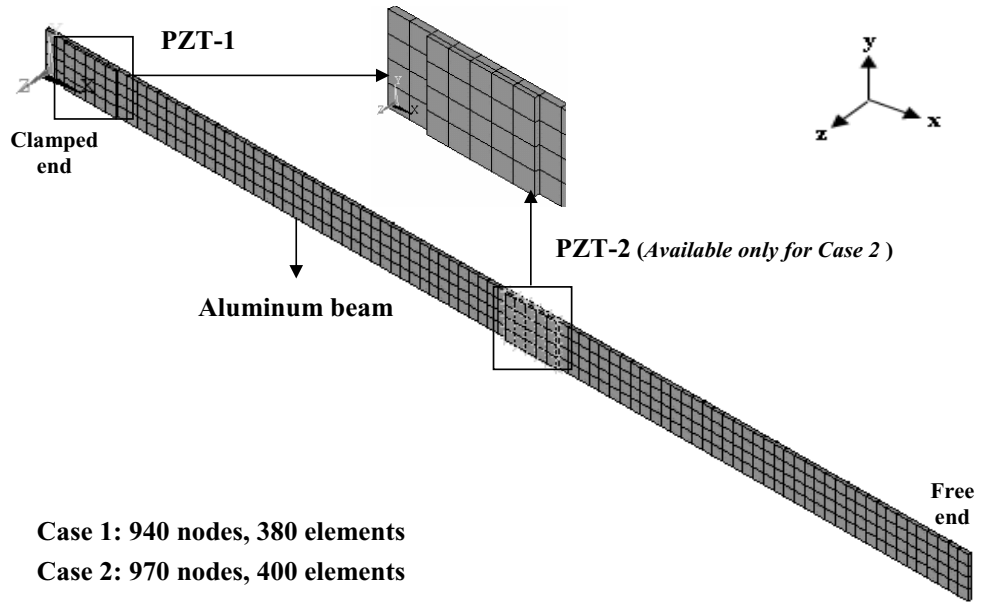

Fig. 2. The FE model of the smart structure for Case 1 and Case 2, aluminum beam of $450 \mathrm{~mm} \times 20 \mathrm{~mm} \times 1.5 \mathrm{~mm}$, and piezoelectric patches of $25 \mathrm{~mm} \times 20 \mathrm{~mm} \times 1 \mathrm{~mm}$.

displacements are exported to a text file. "incon.txt" command file is created from the nodal displacement file by a computer program automatically. VisualBASIC is used for this in this study.

$i$ is the time step number. $n s$ is the total number of steps. $(n s * d t)$ gives the end time for the transient analysis, where the steady-state response is reached. $n s$ is found by dividing $\mathrm{t}_{s}$ to $d t$.

$v s(i)$ is the sensor value at the time step $i$. Knowing the initial conditions at $t=0, v s(l)$ can be calculated by the solve command at the step $i=1$. ANSYS uses the sparse direct solver to solve the equations given in Eq. (3). For the strain feedback, $n 1$ and $n 2$ are the node numbers where the strain is measured in the $\mathrm{x}$ direction. $d x$ is the distance between these nodes. For the displacement feedback, $n r$ is the node number where the displacement is sensed. $k s$ is the sensor amplification value. As seen from the block diagram in Fig. 1, the reference value, $v_{r}$, equals to zero for the vibration cancellation, and the error value at the step $i=1$ can be calculated as $(0-v s(1))$. The error value is multiplied by $k p^{*} k v$ to find $v a(1) . v a(i)$ is the value of the vibration controlling PZT voltage at the step i. $k v$ is the actuator power amplification value and $k p$ is the control gain. $v a(l)$ is assigned to the vibration controlling nodes, which are coupled to the node numbered as na. The $d$ command is used for these assignments. So the first step is accomplished. The loop is continued until $i=n s$.

There are no initial values for Case 2. $v h(i)$ is the value of the vibration generating PZT voltage at the time step $i$. The time history of the vibration generating PZT voltage is known and the samples of $v h()$ are assigned accordingly by the commands in the file "excite.txt". The values of $v h()$ are assigned to the vibration generating nodes, which are coupled to the node numbered as $n h$, in the loop at the corresponding time step as seen in Table 1.

The FE model of the smart structure considered in Case 1 and 2 is shown in Fig. 2. An aluminum beam is used in both cases. The beam is clamped at one end and free at the other end. PZT-1 is for the vibration controlling and is available in both cases. PZT-2 is for the vibration generating and is available only in Case 2 . The aluminum beam has dimensions as $450 \mathrm{~mm} \times 25 \mathrm{~mm} \times 1.5 \mathrm{~mm}$ and PZT patches has dimensions as $25 \mathrm{~mm} \times 20 \mathrm{~mm} \times 1 \mathrm{~mm}$. When the first vibration mode is considered, regions where the maximum strains occur are the best to locate the vibration controlling PZT patch [9]. PZT-1 is located $10 \mathrm{~mm}$ away from the clamped edge and PZT-2 is located in the middle.

Strain gauge location is at the opposite side of the PZT actuator, and $20 \mathrm{~mm}$ away from the clamped end. Free tip of the beam is considered as displacement output for the feedback and response. The strain is in the $\mathrm{x}$ direction, the displacement is in the $\mathrm{z}$ direction.

Young modulus, density and Poisson's ratio for the passive part of the smart beam are $\mathrm{E}=62 \times 10^{9} \mathrm{~N} / \mathrm{m}^{2}$, $\rho=2676 \mathrm{~kg} / \mathrm{m}^{3}$ and $v=0.32$, respectively. The material properties of the PZT patches are given in Table 2 . Damping matrix given in Eq. (4) is built by assuming Rayleigh damping coefficients $(\alpha$ and $\beta)$. These coefficients are determined so that the free vibration response in the experiment approximately matches with the free vibration 
Table 2

Material properties of the PZT patches (PZT-5H)

\begin{tabular}{cccccc}
\hline $\begin{array}{c}\text { Elastic stiffness } \\
\text { matrix } \\
{\left[\mathrm{N} / \mathrm{m}^{2}\right]}\end{array}$ & $\begin{array}{c}\text { Piezoelectric } \\
\text { strain matrix } \\
{\left[{\left.\mathrm{C} / \mathrm{m}^{2}\right]}^{2}\right.}\end{array}$ & $\begin{array}{c}\text { Dielectric } \\
\text { matrix } \\
{[\mathrm{F} / \mathrm{m}]}\end{array}$ & $\begin{array}{c}\text { Density } \\
{\left[\mathrm{kg} / \mathrm{m}^{3}\right]}\end{array}$ \\
\hline $\mathrm{C}_{11}$ & $12.6 \times 10^{10}$ & $\mathrm{E}_{31}$ & 6.5 & $1.503 \times 10^{-8}$ & 7350 \\
$\mathrm{C}_{12}$ & $7.95 \times 10^{10}$ & $\mathrm{E}_{33}$ & 23.3 & $1.503 \times 10^{-8}$ & \\
$\mathrm{C}_{13}$ & $8.41 \times 10^{10}$ & $\mathrm{E}_{15}$ & 17 & $1.3 \times 10^{-8}$ & \\
$\mathrm{C}_{33}$ & $11.7 \times 10^{10}$ & & & & \\
$\mathrm{C}_{44}$ & $2.33 \times 10^{10}$ & & & & \\
\hline
\end{tabular}

Table 3

Specifications of multifunction data acquisition cards in the experiment

\begin{tabular}{lccccccc}
\hline $\begin{array}{l}\text { Multifunction } \\
\text { DAQ cards }\end{array}$ & Bus & $\begin{array}{c}\text { Analog } \\
\text { inputs }\end{array}$ & $\begin{array}{c}\text { Input rate } \\
(\mathrm{kS} / \mathrm{s})\end{array}$ & $\begin{array}{c}\text { Analog } \\
\text { outputs }\end{array}$ & $\begin{array}{c}\text { Output rate } \\
(\mathrm{kS} / \mathrm{s})\end{array}$ & $\begin{array}{c}\text { Output range } \\
(\mathrm{V})\end{array}$ & $\begin{array}{c}\text { Digital } \\
\text { I/O }\end{array}$ \\
\hline PCI 6220 & PCI & 16 & 250 & - & - & - & 24 \\
PCI 6722 & PCI & - & - & 8 & $182 \mathrm{k}$ to $800 \mathrm{k}$ & \pm 10 & 8 \\
DAQPad 6015 & USB & 16 & 200 & 2 & 0.3 & \pm 10 & 8 \\
\hline
\end{tabular}

response in the simulation. They are taken as $\alpha=0.040 \%, \beta=0.027 \%$ for Case 1 , and $\alpha=0.14 \%, \beta=0.07 \%$ for Case 2.

The first mode is considered as the highest mode for the calculation of the time step. The undamped frequency for the first mode is found as $6.27 \mathrm{~Hz}$ for Case 1 and $6.129 \mathrm{~Hz}$ for Case 2 . The time steps chosen as $\Delta \mathrm{t}=1 /\left(20 \mathrm{f}_{1}\right)$ are calculated as $0.00797 \mathrm{~s}$ for Case $1,0.00816 \mathrm{~s}$ for Case 2. The damping ratio for the first mode is found as 0.0053 for Case 1, 0.0169 for Case 2.

The tip displacement $\delta_{0}$ is taken as $24.5 \mathrm{~mm}$ for Case 1 . The samples of the harmonic excitation for Case 2 is calculated by $v h(i)=270 * \sin (2 * \pi * f * t)$. $f$ is taken as $6.129 \mathrm{~Hz}$, which is the fundamental frequency.

Considering the experimental setup, the power amplification, $\mathrm{K}_{v}$ is taken as 30 . The sensor amplification gain, $\mathrm{K}_{s}$, is taken as 10000 for strain feedback, 250 for displacement feedback.

As an example for the simulation result in Case 1 , Control OFF $\left(\mathrm{K}_{p}=0\right)$ and Control ON $\left(\mathrm{K}_{p}=9\right)$ responses including displacement output, strain output and actuation voltage are shown in Fig. 3. Further results and comments for Case 1 and Case 2 are given in Section $4 . \mathrm{K}_{p}$ corresponds to $k p$ in the code.

\section{Experimental system}

Schematic and photographic views of the experimental system used in the study are shown in Fig. 4. The experimental system includes smart beams, a digital control system, a strain gauge input module (NI SC-SG01) and a signal conditioning unit (NI SC-2345) of National Instruments, a non-contact laser displacement sensor (LK-G157) of Keyence, a high voltage power amplifier of Sensortech (SA-10). Smart structures in two cases are prepared by bonding PZT patches onto the beam using ELECOLIT 325 conductive epoxy. The wires are soldered on the PZT patches with S-Sn60/Pb40 solder. TML FRA-3-11-1L type strain gauges $(3 \mathrm{~mm}, 120 \mathrm{ohm}$, gage factor $=2)$ are located in the $\mathrm{x}$ direction.

A digital control system is built in personal computer and multifunction data acquisition cards (DAQpad-6015, PCI-6220, PCI-6722) of National Instruments and LabVIEW software. Specifications of the cards used in the experiment are given in Table 3.

Closed loop control in LabVIEW (7.0) is accomplished with a standard "while" loop and a "shift register" which carries values from one iteration step to the next. The feedback data is recorded via analog input (AI) cards. Feedback signals are compared to a reference value which equals to zero to eliminate vibrations. The error and control signal is calculated and then the control signal is simultaneously sent to the amplifier via analog output card (AO) to actuate PZT patch. Control OFF and Control ON signals for the smart structures are obtained as the program outputs. A low-pass filter whose cut off frequency is $30 \mathrm{~Hz}$ is used to obtain these signals. The input and output signals of the amplifier are limited by $\pm 9 \mathrm{~V}$ and $\pm 270 \mathrm{~V}$, respectively. 

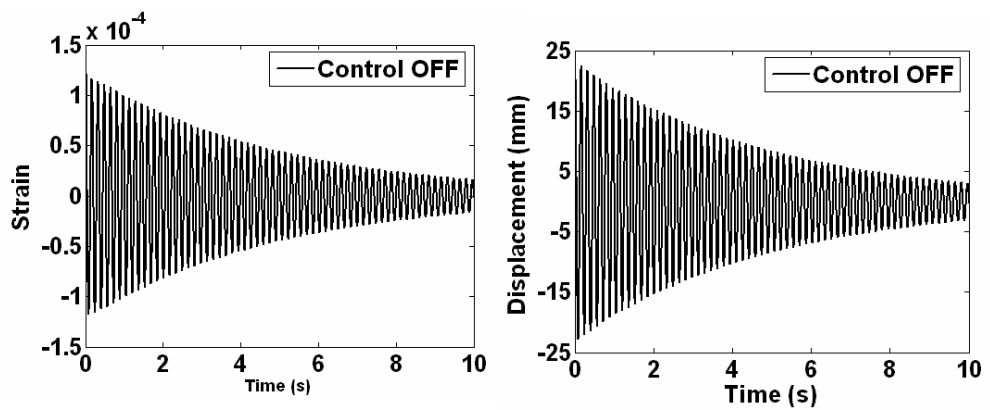

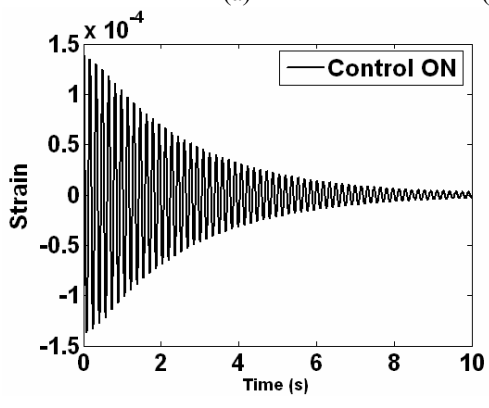

(b)

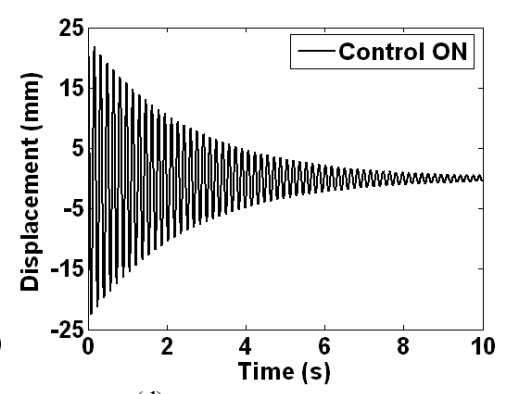

(d)

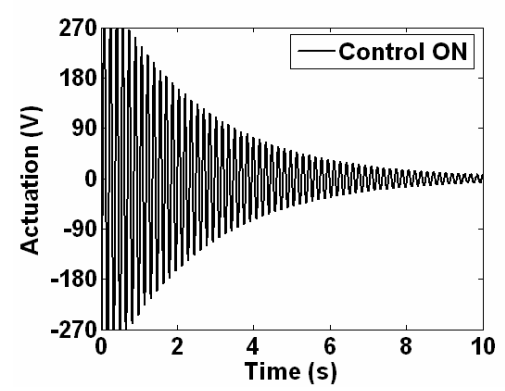

(e)

Fig. 3. Case 1 simulation results with strain feedback control for $\mathrm{K}_{p}=9$.

Synchronization of multiple DAQ cards is important for acquiring and sending data in real-time control. Multiple DAQ cards are used in the experiments. Some delay occurs between input-output signals when the low sampling rates are chosen. So, the sampling rate is increased as higher as possible in the closed loop control experiments. Sampling rate is set to $18000 \mathrm{~Hz}$ to realize a real-time control. Higher sampling rates are chosen since there is a delay while sending control signals.

Two types of feedbacks are used for the control of smart structures. In strain feedback, the strain data is recorded with the AI card (PCI-6220) through the input module and the signal conditioning unit. The quarter bridge mode is used in the strain gauge configuration. In displacement feedback, laser sensor located at the free tip of the beam is used. Displacement data is recorded through another multifunction card (DAQPad 6015). Laser sensor measures displacements up to $\pm 40 \mathrm{~mm}$ corresponding to $\pm 10 \mathrm{~V}$. The same sensor $\left(\mathrm{K}_{s}\right)$ and power amplification $\left(\mathrm{K}_{v}\right)$ gains are used in the experiments as given in Section 2.2.

In Case 1, a tip displacement is initiated with a solenoid shaft located at the free end. The program developed in LabVIEW consists of 7 sequences including AI, AO and digital output (DO) applications. The schematic view of the program is shown in Fig. 5(a). 1, 3, 5 and 7 sequences control DO that enables the pushing and the pulling of the solenoid shaft. Control OFF and Control ON signals of the smart structure are obtained in the sequences 2 and 6. An experimental result is shown in Fig. 5(b) as an example (see the simulation result in Fig. 3 for comparison). The sequence 4 is a waiting mode to pass Control $\mathrm{ON}$ test. The experiment is repeated for various gain values. 


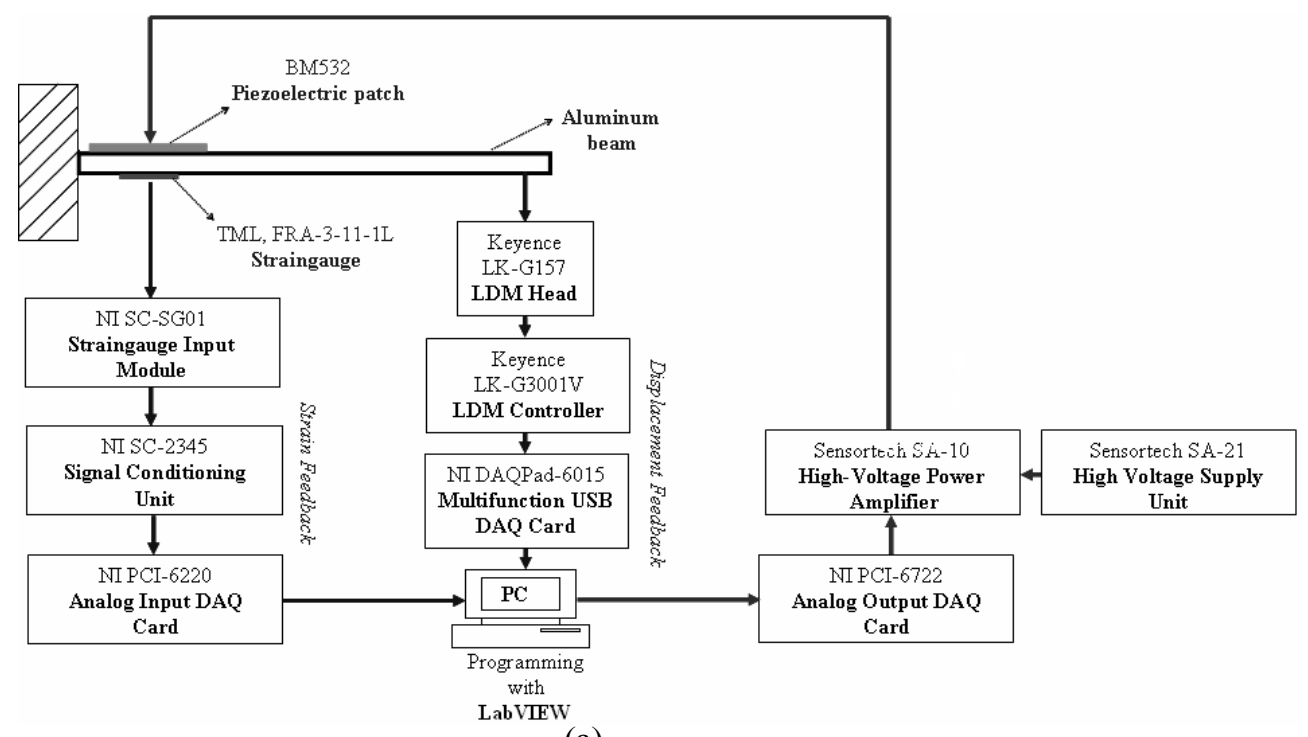

(a)
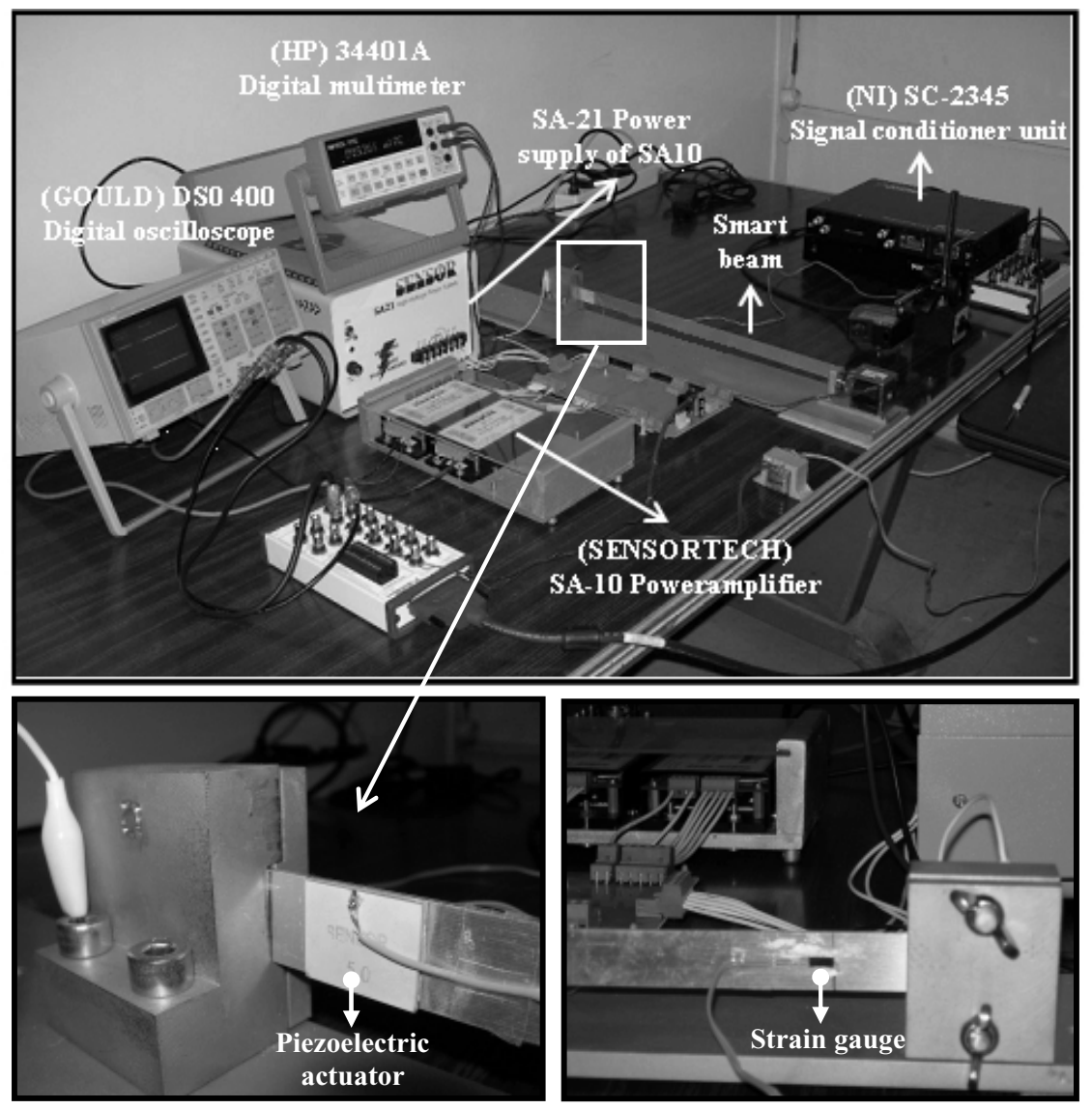

(b)

Fig. 4. Experimental setup (a) schematic view for Case 1, (b) photographic view. 


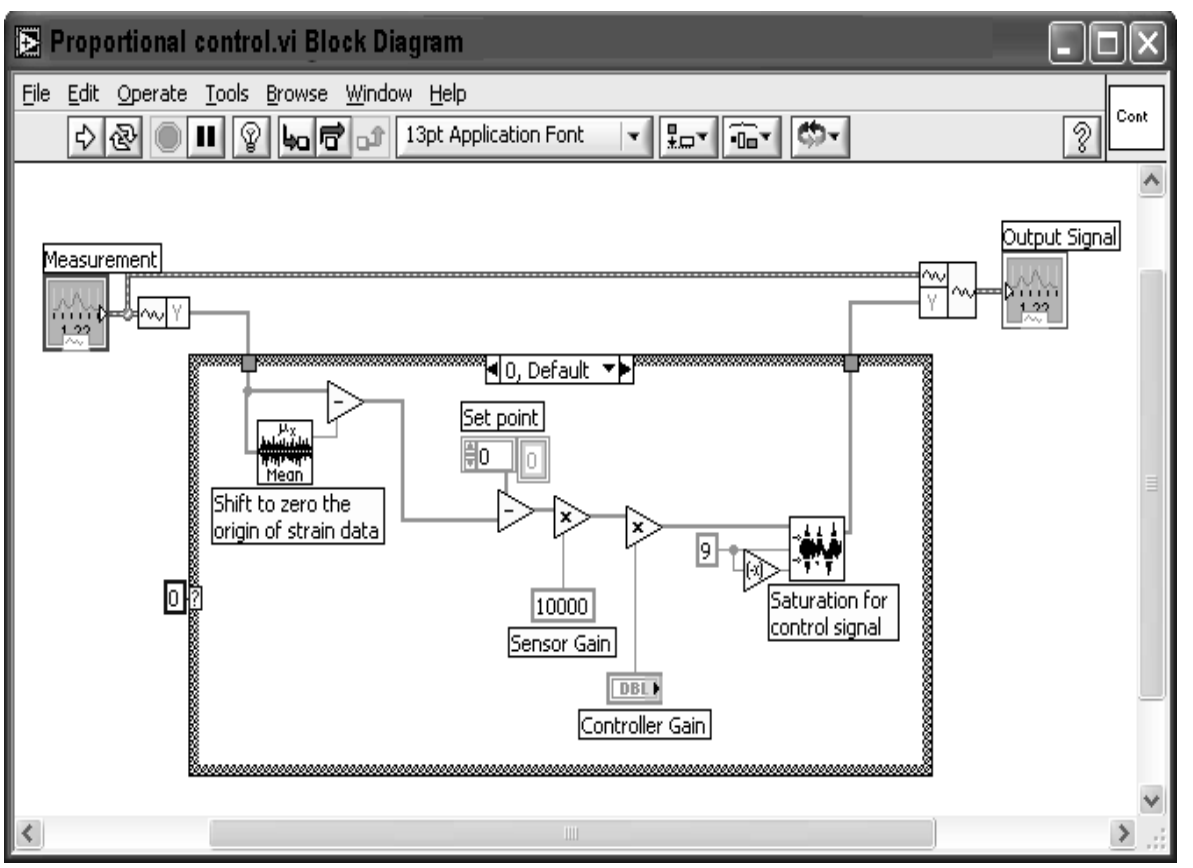

(a)

\section{Experiment}

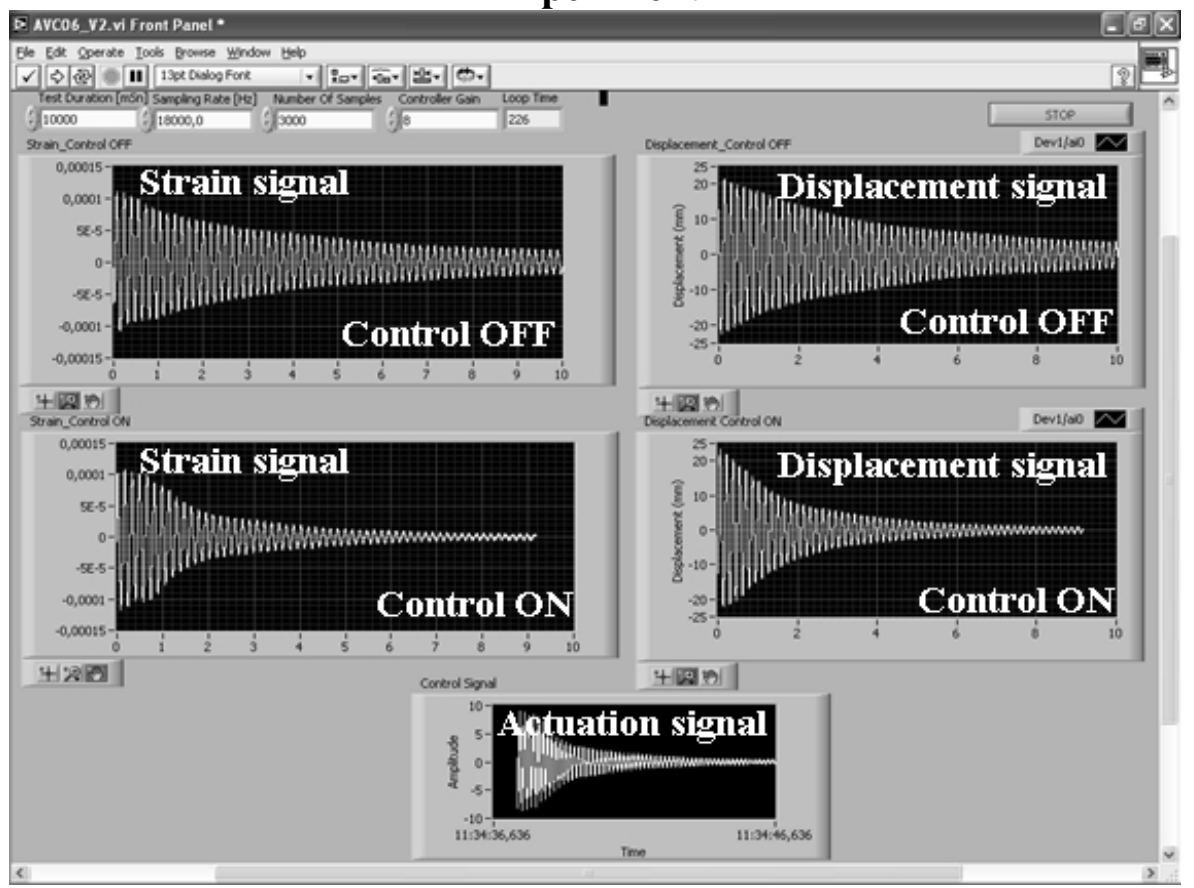

(b)

Fig. 5. The developed LabVIEW program, (a) control part of the code, (b) Case 1 experimental results for $\mathrm{K}_{p}=9$. 

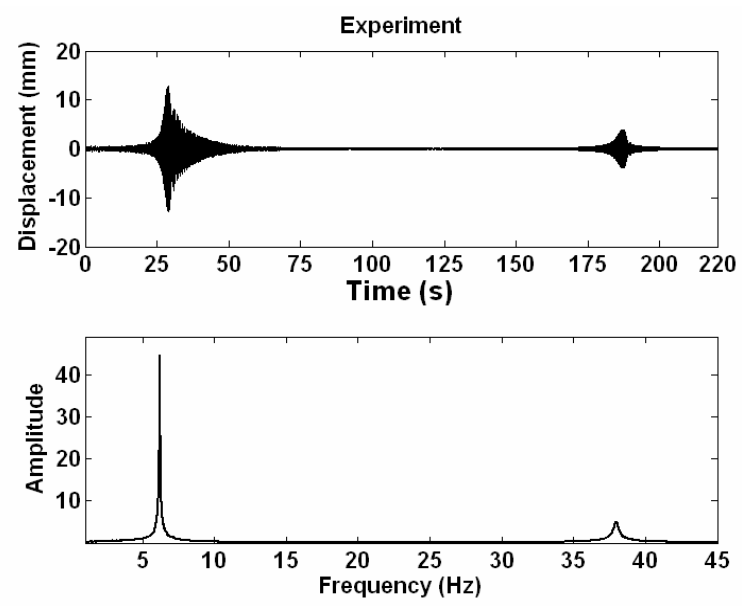

Fig. 6. Experimental results on time and frequency domain in Case 1.

Table 4

Natural frequencies of the smart beams considered in Case 1 and Case 2

\begin{tabular}{|c|c|c|c|c|}
\hline \multirow[t]{2}{*}{ Natural Frequency } & \multicolumn{2}{|c|}{ Case 1} & \multicolumn{2}{|c|}{ Case 2} \\
\hline & $\begin{array}{c}\text { Simulation } \\
{[\mathrm{Hz}]}\end{array}$ & $\begin{array}{c}\text { Experiment } \\
{[\mathrm{Hz}]}\end{array}$ & $\begin{array}{c}\text { Simulation } \\
{[\mathrm{Hz}]}\end{array}$ & $\begin{array}{c}\text { Experiment } \\
{[\mathrm{Hz}]}\end{array}$ \\
\hline 1 & 6.270 & 6.220 & 6.129 & 6.128 \\
\hline 2 & 38.599 & 37.990 & 36.604 & 35.122 \\
\hline
\end{tabular}

In Case 2, a sine excitation generated from the second channel of the AO card is applied to the vibration generating PZT patch. The computed control signal is simultaneously sent to the amplifier via the first channel of the AO card to actuate the vibration controlling PZT patch.

\section{Simulation and experimental results}

\subsection{Modal analysis}

Experimental modal analysis is performed using chirp signals. The chirp signal with the amplitude of $270 \mathrm{~V}$ is swept to determine natural frequencies of the smart beams. The tip displacement of the beam is measured by the laser sensor while the excitation continues. The frequency response is found in MATLAB by taking the Fast Fourier Transform (FFT) of the time response. Initial and target frequency, frequency step $(\Delta \mathrm{f})$ and amplitude for the chirp signal can be set with the program used in the experiment. Sampling rate is taken as $4096 \mathrm{~Hz}$.

In order to find the first two natural frequencies, the frequency of the chirp signal $(\Delta \mathrm{f}=0.1 \mathrm{~Hz})$ is changed from $0.1 \mathrm{~Hz}$ to $45 \mathrm{~Hz}$ for $220 \mathrm{~s}$. The experimental time and frequency responses for Case 1 are shown in Fig. 6.

For the comparison of the experimental and simulation results, the other chirp signal $(\Delta f=0.02 \mathrm{~Hz})$ whose the frequency changes from $5 \mathrm{~Hz}$ to $7 \mathrm{~Hz}$ for $50 \mathrm{~s}$ is used to find the first natural frequency. Experimental results for Case 1 are shown in Fig. 7(a).

The simulation is performed by applying the chirp signal to the PZT actuator in the FE model. The simulation results for Case 1 are shown in Fig. 7(b). In the frequency domain, the experimental and simulation results for the first mode are very close to each other. The comparison of the experimental and simulation natural frequencies for Case 1 and Case 2 is given in Table 4. It is noted that the PZT shaker decreases the natural frequencies of the smart structure in Case 2. 

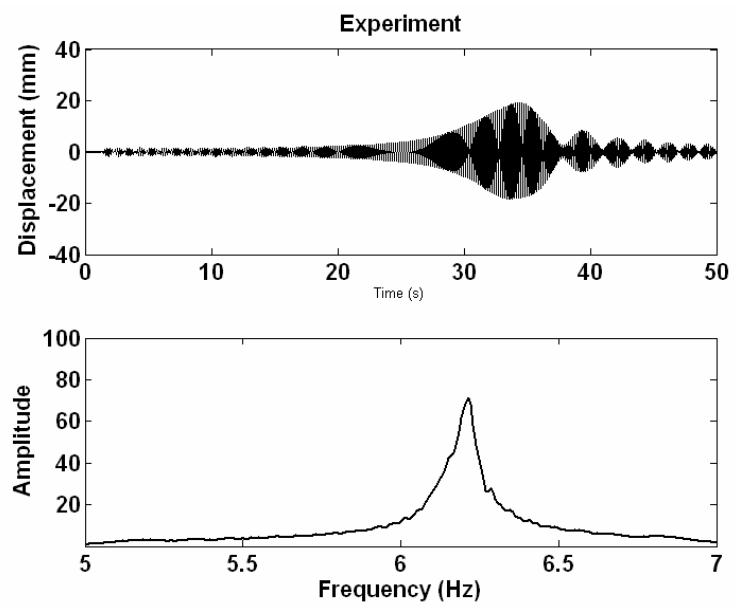

(a)
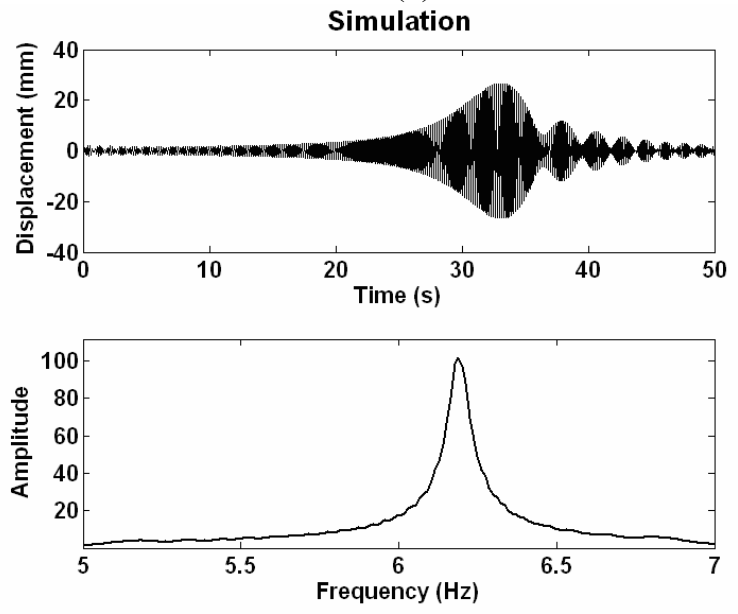

(b)

Fig. 7. Results for the first natural frequency in Case 1, (a) experimental and (b) simulation.

Table 5

Decaying times for Case 1

\begin{tabular}{ccccccc}
\hline \multicolumn{3}{c}{ Strain feedback control } & & \multicolumn{3}{c}{ Displacement feedback control } \\
\cline { 1 - 2 } Gains & Simulation & Experiment & & Gains & Simulation & Experiment \\
\hline $\mathrm{K}_{p}=0$ & $\mathrm{t}_{\ell}=9.98$ & $\mathrm{t}_{\ell}=9.96$ & & $\mathrm{~K}_{p}=0$ & $\mathrm{t}_{\ell}=9.98$ & $\mathrm{t}_{\ell}=9.96$ \\
$\mathrm{~K}_{p}=5$ & $\mathrm{t}_{c}=7.12$ & $\mathrm{t}_{c}=5.13$ & & $\mathrm{~K}_{p}=1$ & $\mathrm{t}_{c}=7.36$ & $\mathrm{t}_{c}=5.10$ \\
$\mathrm{~K}_{p}=9$ & $\mathrm{t}_{c}=5.13$ & $\mathrm{t}_{c}=3.67$ & & $\mathrm{~K}_{p}=2$ & $\mathrm{t}_{c}=5.86$ & $\mathrm{t}_{c}=3.23$ \\
\hline
\end{tabular}

\subsection{Case1: Free vibration control}

First, strain feedback is used for vibration suppression of the smart beam. Control OFF and Control ON vibration responses for the control gain values, $\mathrm{K}_{p}=5$ and $\mathrm{K}_{p}=9$ are shown in Fig. 8. The corresponding actuation voltages applied to the PZT patch are shown in Fig. 9. As seen from Fig. 9(b) and (d), there is a saturation point for a short time of $0.8 \mathrm{sec}$. since actuation voltages exceed $\pm 270 \mathrm{~V}$. This saturation point is also adopted in the simulation because of the experimental limitations. The maximum voltage to be applied is about $500 \mathrm{~V}$ per thickness (mm) for Sensortech BM532 PZT patches [20]. 


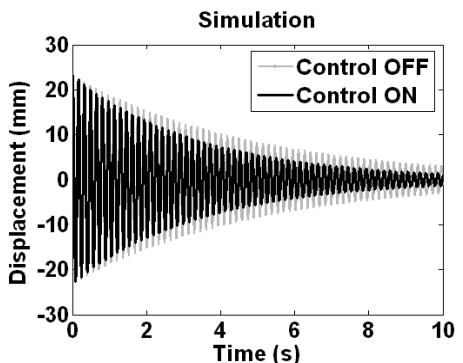

(a)

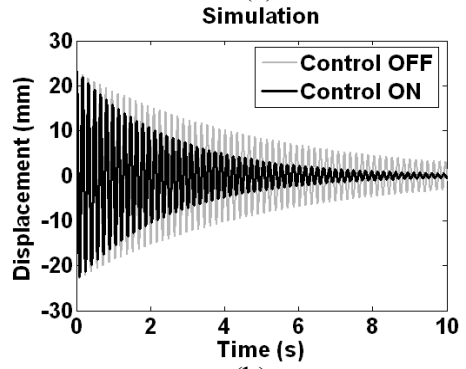

(b)

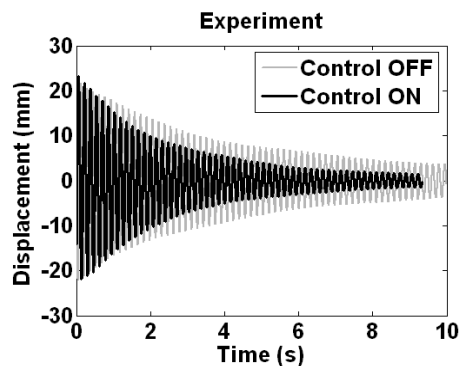

(c)

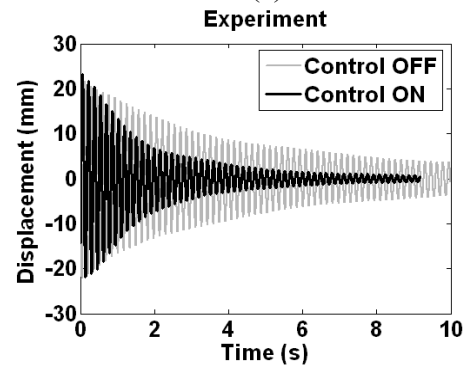

(d)

Fig. 8. Case 1 vibration responses for strain feedback control, simulation for (a) $\mathrm{K}_{p}=5$ and (b) $\mathrm{K}_{p}=9$, experiment for (c) $\mathrm{K}_{p}=5$ and (d) $\mathrm{K}_{p}=9$.

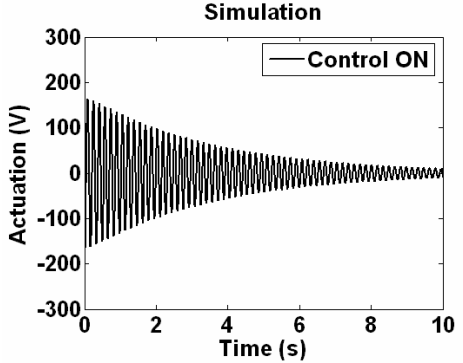

(a)

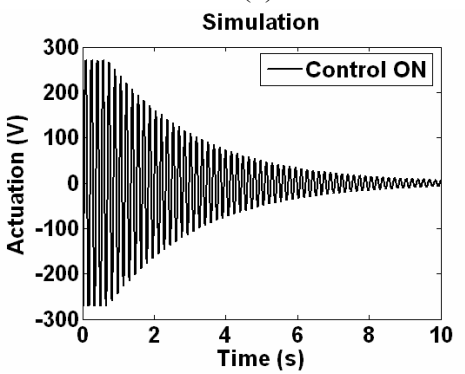

(b)

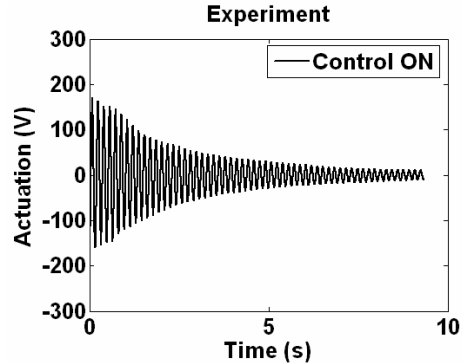

(c)

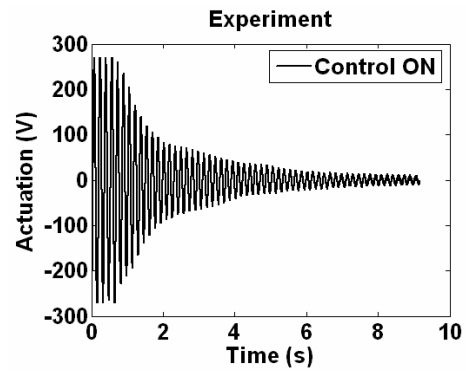

(d)

Fig. 9. Case 1 actuation voltages for strain feedback control.

Then displacement feedback is considered for vibration suppression of the smart beam. The effectiveness of the displacement feedback control is tested for the gain values of $\mathrm{K}_{p}=1$ and $\mathrm{K}_{p}=2$. The controller gains are chosen in order to get similar control performances with strain feedback. The comparison of experimental results with the FE simulation results is shown in Fig. 10. The amplitudes of the free vibration are also reduced with displacement feedback. Corresponding actuation voltages are shown in Fig. 11.

Let the last peak be $\mathrm{y}_{\ell}$ at $\mathrm{t}=\mathrm{t}_{\ell}$ for the Control OFF responses. Let $\mathrm{t}_{c}$ be the time at which the peak approximately 


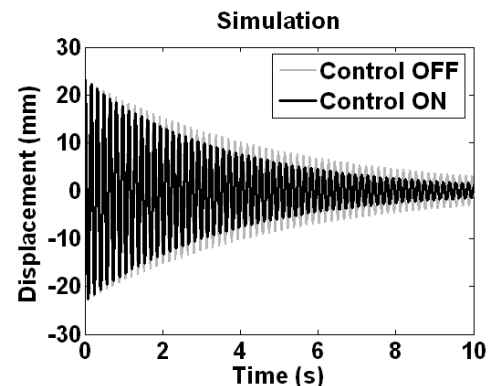

(a)

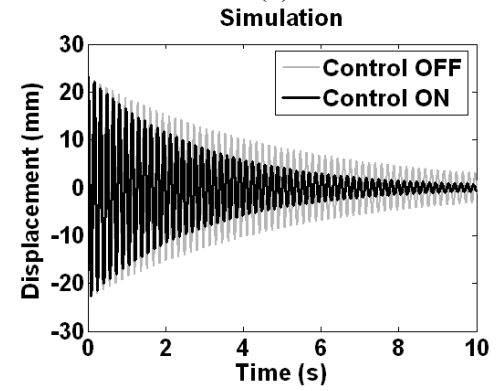

(b)

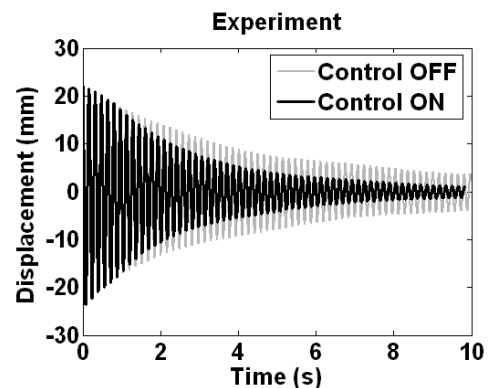

(c)

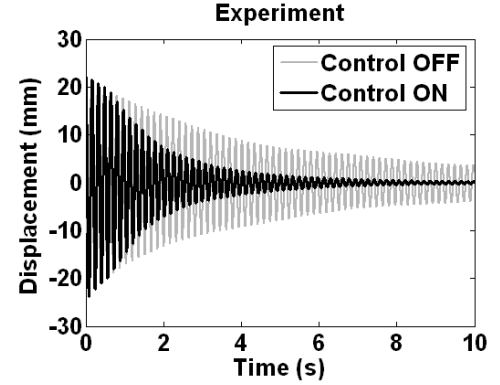

(d)

Fig. 10. Case 1 vibration responses for displacement feedback control, simulation for (a) $\mathrm{K}_{p}=1$ and (b) $\mathrm{K}_{p}=2$, experiment for (c) $\mathrm{K}_{p}=1$ and (d) $\mathrm{K}_{p}=2$.

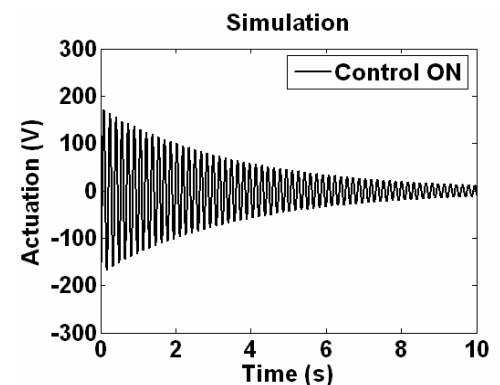

(a)

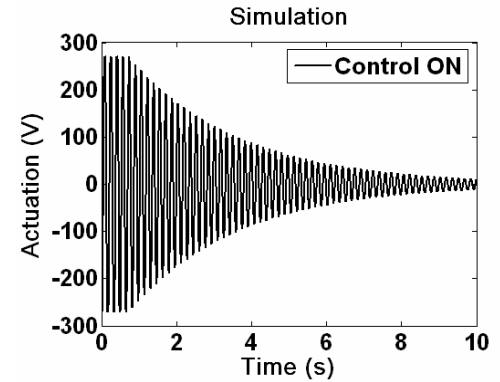

(b)

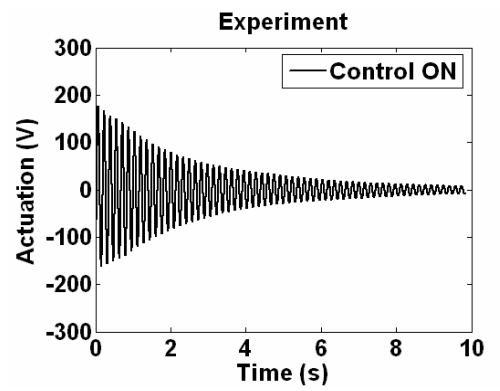

(c)

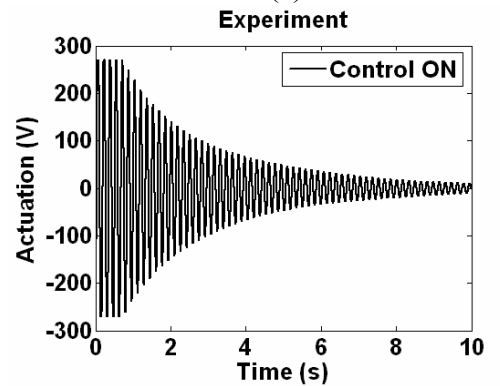

(d)

Fig. 11. Case 1 actuation voltages for displacement feedback control.

equals to $\mathrm{y}_{\ell}$ for the Control ON responses. The values found are given in Table 5. As seen from the table and figures, the decaying times decrease as the controller gains increase. The control gain is limited by the maximum actuation voltage which can be applied to the PZT patch safely. 


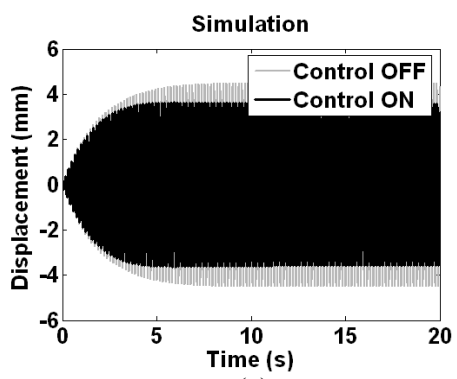

(a)

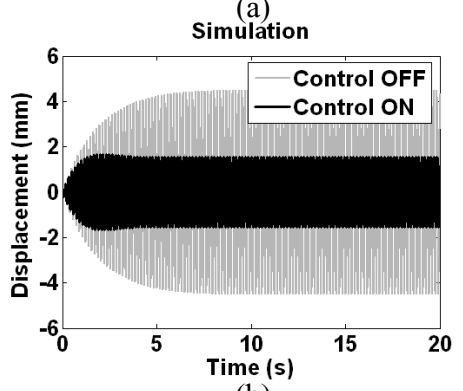

(b)

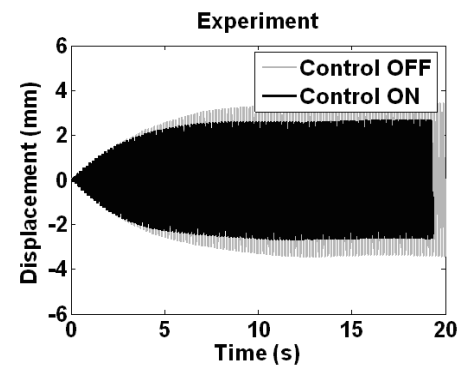

(c)

Experiment

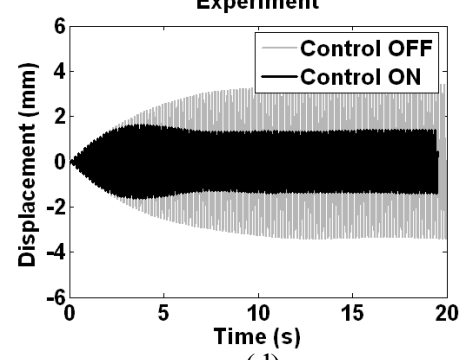

(d)

Fig. 12. Case 2 vibration responses for strain feedback control, simulation for (a) $\mathrm{K}_{p}=3.75$ and (b) $\mathrm{K}_{p}=15$, experiment for (c) $\mathrm{K}_{p}=3.75$ and (d) $\mathrm{K}_{p}=15$.

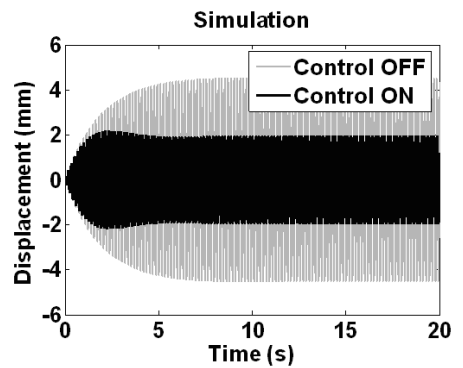

(a)

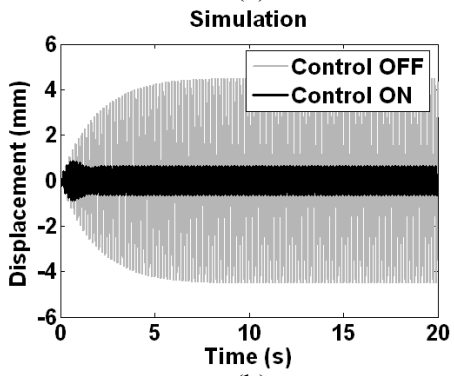

(b)

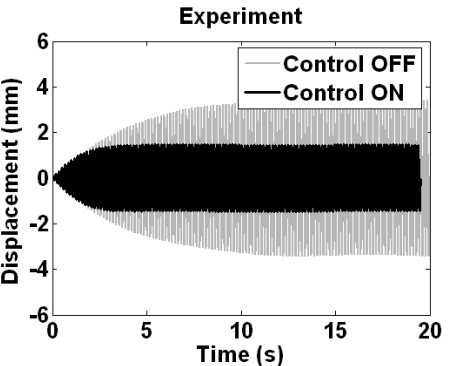

(c)

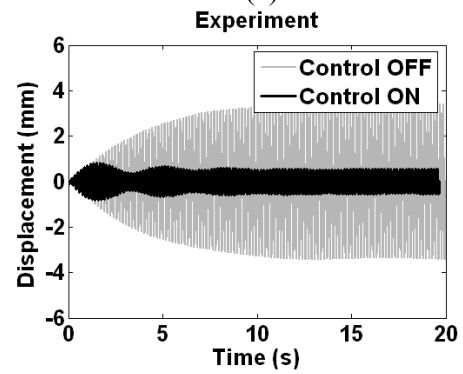

(d)

Fig. 13. Case 2 vibration responses for displacement feedback control, simulation for (a) $\mathrm{K}_{p}=3.75$ and (b) $\mathrm{K}_{p}=15$, experiment for (c) $\mathrm{K}_{p}=$ 3.75 and (d) $\mathrm{K}_{p}=15$.

\subsection{Case 2: Forced vibration control}

The control action is started at $\mathrm{t}=0 \mathrm{~s}$ in order to decrease steady state vibration amplitudes of the smart beam under harmonic excitation. Control OFF and Control ON vibration responses for strain and displacement feedbacks are shown in Figs 12-13. 
In the forced vibration control, results are obtained for the gains $\mathrm{K}_{p}=3.75$ and $\mathrm{K}_{p}=15$. In the numerical simulations, strain and displacement feedback controls provide $63 \%$ and $87 \%$ reduction in steady-state vibration amplitudes, respectively. In terms of maximum actuation values, strain and displacement feedback controls require $59 \mathrm{~V}$ and $95 \mathrm{~V}$, respectively. Similarly, experimental results show that strain and displacement controls provide $61.5 \%$ and $85 \%$ reduction in the steady-state amplitudes, respectively. In terms of maximum actuation values, strain and displacement feedback controls require $63 \mathrm{~V}$ and $92 \mathrm{~V}$, respectively. Simulation results show that the displacement feedback control is more effective since it enables to apply higher actuation voltages for the same gain values.

\section{Conclusions}

Users of commercial FE programs such as ANSYS can analyze systems by defining their systems and the inputs. These programs develop the mathematical models of the systems and perform their solutions. It is possible to extract the mathematical models from the commercial FE programs and then these models can be used in other commercial control programs such as MATLAB to solve closed loop problems. By incorporating the control law directly into the FE programs, the closed loop control problems with complex structures can be analyzed more easily.

The closed loop simulation results are verified by the experiments. The experimental system is introduced in detail. The smart cantilever beams with the PZT patches having two different configurations are considered in the study. Modal analysis is done by chirp signals considering the first two modes. Active control of the free and the forced vibrations is performed using displacement and strain feedback signals. Free and steady-state vibration amplitudes of the smart beams are successfully reduced with the active control in both the experiment and the simulation. It is observed that the simulation results match well with the experimental results.

The ICFES can be extended to various engineering structures under various loading. The locations and sizes of vibration controlling actuators and closed loop control parameters can be determined by the simulation before the realization of the actual system.

\section{Acknowledgment}

The authors acknowledge Turkish Scientific and Research Council (TUBITAK) for the financial support (Project Number: 104M373).

\section{References}

[1] A. Jnifene, Member, IEEE and W. Andrews, Experimental study on active vibration control of a single-link flexible manipulator using tools of fuzzy logic and neural networks, IEEE Transactions on Instrumentation and Measurement 54 (2005), 1200-1208.

[2] J.L. Meyer, W.B. Harrington, B.N. Agrawal and G. Song, Vibration suppression of a spacecraft flexible appendage using smart material, Smart Material and Structures 7 (1998), 95-104.

[3] M.M. Torbati, A.J. Keane, S.J. Elliott, M.J. Brennan, D.K. Anthony and E. Rogers, Active vibration control (AVC) of a satellite boom structure using optimally positioned stacked piezoelectric actuators, Journal of Sound and Vibration 292 (2006), 203-220.

[4] G. Song, V. Sethi and H.-N. Li, Vibration control of civil structures using piezoceramic smart materials: A review, Engineering Structures 28 (2006), 1513-1524.

[5] J. Mackerle, Smart materials and structures-a finite element approach: bibliography (1986-1997), Modelling and Simulation in Materials Science and Engineering 6 (1998), 293-334.

[6] A. Benjeddou, Advances in piezoelectric finite element modeling of adaptive structural elements: a survey, Computers \& Structures 76 (2000), 347-363.

[7] J. Mackerle, Smart materials and structures - a finite element approach - an addendum: a bibliography (1997-2002), Modelling and Simulation in Materials Science and Engineering 11 (2003), 707-744.

[8] C.M. Reaves and L.G. Horta, Piezoelectric actuator modeling using MSC/NASTRAN and MATLAB. NASA/TM-2003-212651, Langley Research Center, Hampton, Virginia, 2003.

[9] S.X. Xu and T.S. Koko, Finite element analysis and design of actively controlled piezoelectric smart structures, Finite Elements in Analysis and Design 40 (2004), 241-262. 
[10] B. Seba, J. Ni and B. Lohmann, Vibration attenuation using a piezoelectric shunt circuit based on finite element method analysis, Smart Materials and Structures 15 (2006), 509-517.

[11] U. Gabbert, T.M. Trajkov and H. Köppe, Modelling, Control and simulation of piezoelectric smart structures using finite element method and optimal control, Mechanics, Automatic Control and Robotics 3 (2002), 417-430.

[12] R. Jha and J. Rower, Experimental investigation of active vibration control using neural networks and piezoelectric actuators, Smart Materials and Structures 11 (2002), 115-121.

[13] Z.K. Kusculuoglu, B. Fallahi and T.J. Roston, Finite Element Model of a Beam with a Piezoceramic Actuator, Journal of Sound and Vibration 276 (2004), 27-44.

[14] H. Karagülle, L. Malgaca and H.F. Öktem, Analysis by active vibration control in smart structures by ANSYS, Smart Materials and Structures 13 (2004), 661-667.

[15] G. Meng, L. Yeb, X.J. Dong and K. Wei, Closed loop finite element modeling of piezoelectric smart structures, Shock and Vibration 13 (2006), 1-12.

[16] X.J. Dong, G. Meng and C.J. Peng, Vibration control of piezoelectric smart structures based on system identification technique: Numerical simulation and experimental study, Journal of Sound and Vibration 297 (2006), 680-693.

[17] ANSYS, 2004. ANSYS User Manual, ANSYS, Inc., Canonsburg, PA, USA, (www.ansys.com).

[18] A. Preumont, Vibration Control of Active Structures an Introduction, (2th ed.), Netherlands, Kluwer Academic Publishers, 2002.

[19] L. Malgaca, Integration of active vibration control methods with the finite element models of smart structures, Ph.D. Dissertation, Graduate School of Natural and Applied Sciences, Dokuz Eylïl University, 2007.

[20] Sensor Technology Limited, Ontario, Canada (www.sensortech.ca). 

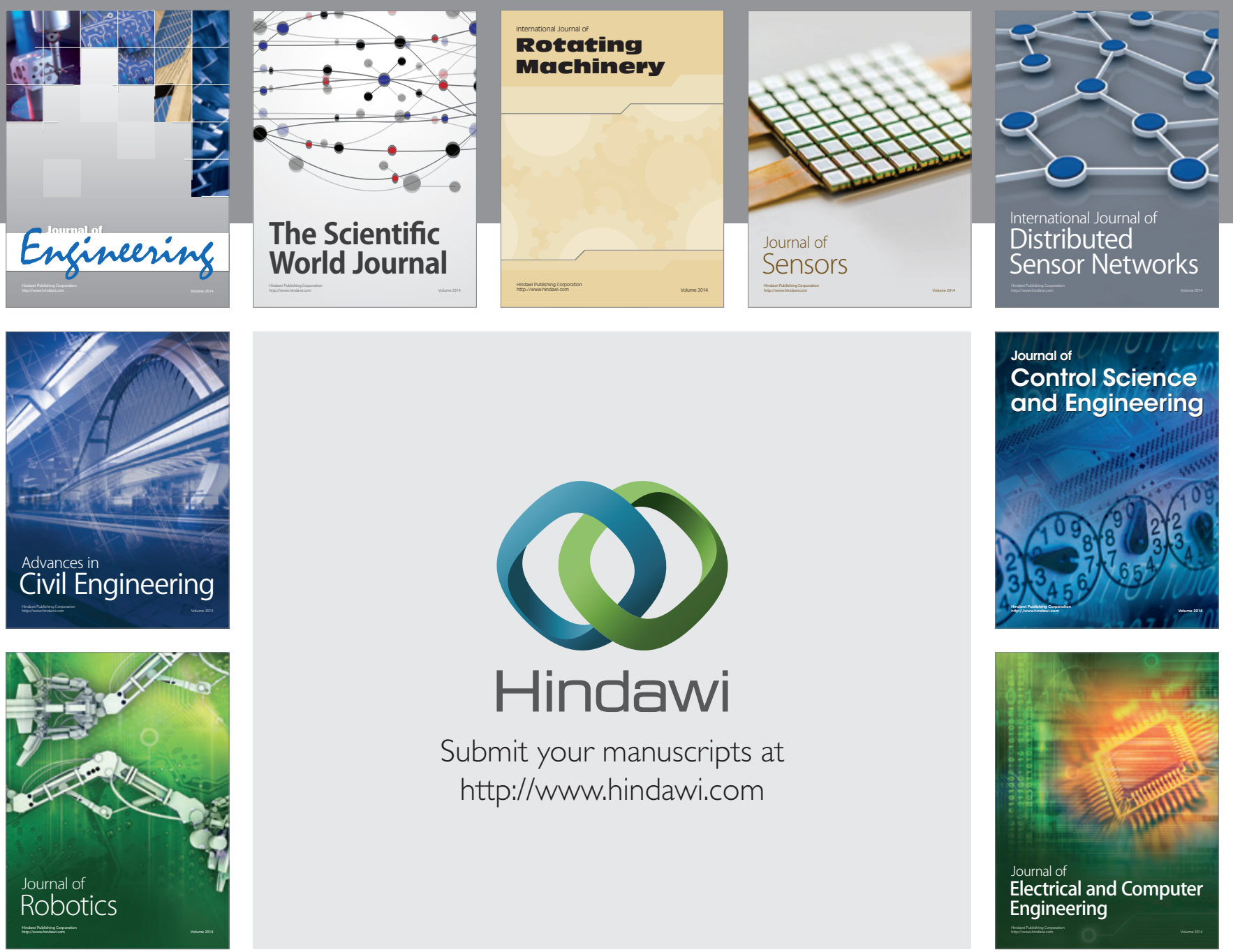

Submit your manuscripts at

http://www.hindawi.com
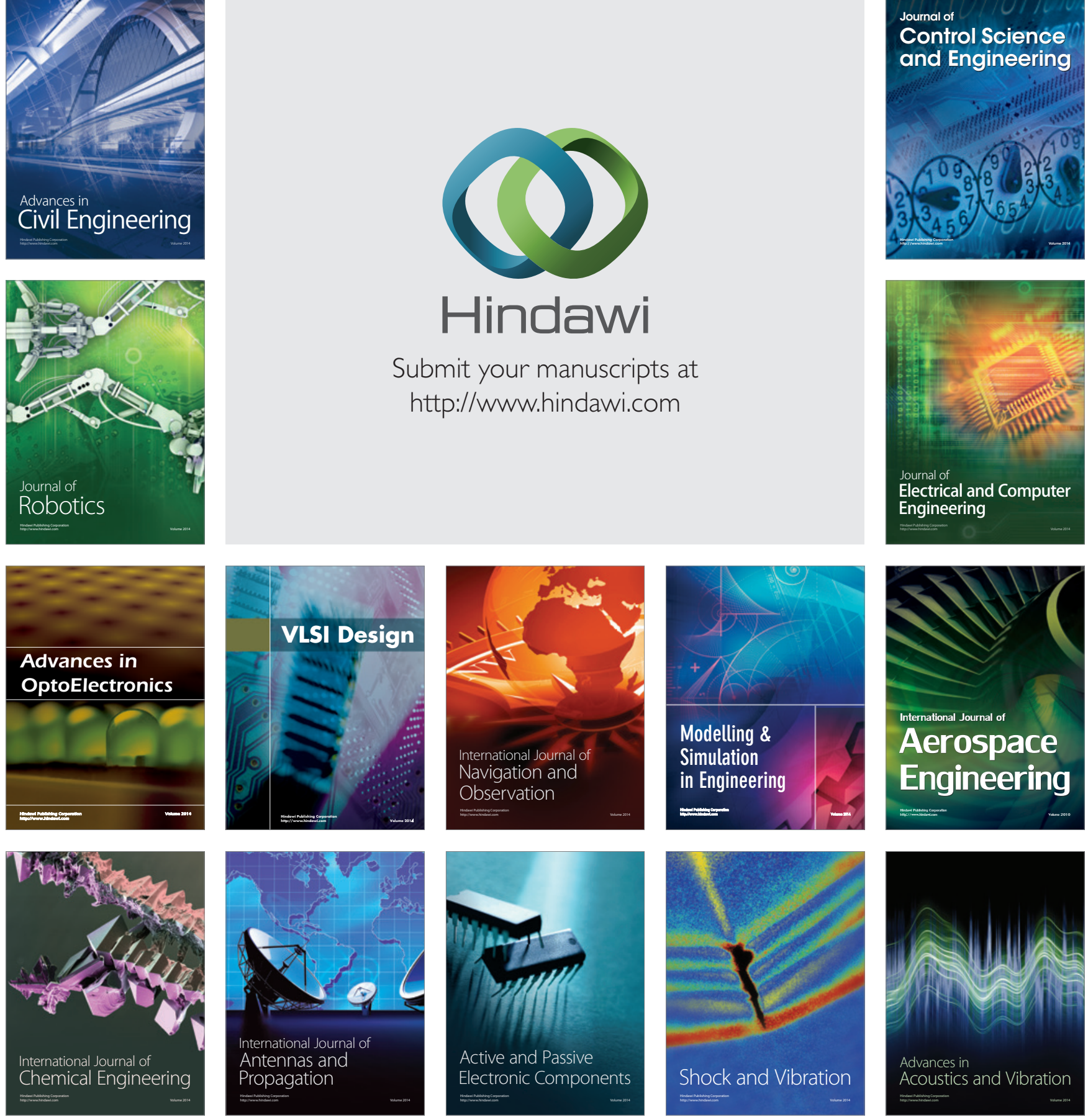